\title{
THE INFLUENCE OF THE FILM FORMED ON THE PRATO CHEESE SURFACE DURING THE NaCI AND KCI SALTING PROCESS: APPLICATION OF THE FINITE ELEMENT METHOD AND NEURAL NETWORKS OF THE SELF-ORGANIZING MAP (SOM) AND MULTILAYER PERCEPTRON (MLP) TYPES
}

\author{
Dionisio Borsato $^{\mathrm{a}, *,(0)}$, Hágata C. Silva ${ }^{\mathrm{a}}$, Ana Carolina G. Mantovani ${ }^{\mathrm{b}}$, Marco A. J. Clemente ${ }^{\mathrm{a}}$, Talita F. de Oliveira ${ }^{\mathrm{a}}$ and \\ Karina B. Angilellia \\ aDepartamento de Química, Universidade Estadual de Londrina, 86057-970 Londrina - PR, Brasil \\ bDepartamento de Física, Universidade Estadual de Londrina, 86057-970 Londrina - PR, Brasil
}

Recebido em 22/09/2021; aceito em 20/12/2021; publicado na web em 07/03/2022

\begin{abstract}
Sodium chloride is used in the cheese salting process as it promotes sensory changes and food preservation. However, in excess can cause hypertension problems, and for this reason, it has been partially replaced by potassium chloride. In the present work, Prato cheese was subjected to joint diffusion of $\mathrm{NaCl}$ and $\mathrm{KCl}$ by immersion in static and stirred brine. The salt concentration values on the cheese surface were determined as a function of time. They were tabulated and presented to the self-organizing map (SOM)-type neural networks and the multilayer perceptron (MLP) for analysis and modeling of the film formed on the surface of the cheese during static and dynamic salting. The SOM network showed that the behavior of the diffusive process, on the surface of the cheese, depends on the analyzed position and that the points in which occupy similar positions, concerning the distance from the edge, have similar behavior. Regression models for $\mathrm{NaCl}$ and $\mathrm{KCl}$ were significant at the $5 \%$ level and can be used for predictive purposes.
\end{abstract}

Keywords: Prato cheese; brine; low sodium; SOM; MPL; neural networks.

\section{INTRODUCTION}

Cheese is an important food with high nutritional value and is part of the daily diet around the world. Among the various types of cheese available on the market, Prato cheese stands out for its nutritional value. ${ }^{1,2}$ Among the components involved in its production, sodium chloride has an outstanding role, as in addition to providing flavor, it participates in aroma development. It also controls moisture, microbial growth, and activity, the activity of various enzymes, and act on product conservation and whey expulsion. Therefore, salting is an important operation in cheese making, generally occurring between the end of pressing and the beginning of ripening. ${ }^{3-5}$

Cheese consumption represents a major contribution to sodium intake and when consumed in excess can lead to increased blood pressure. To minimize this risk, many consumers have been looking for products with lower sodium chloride content. ${ }^{6}$ Therefore, the production of Prato cheeses with a reduction or with a partial replacement of this salt is necessary, as long as it maintains the quality in the product's sensory characteristics. $\mathrm{KCl}$ can be used as a partial substitute in up to $30 \%$ without affecting physicochemical or sensory characteristics due to its similar properties to $\mathrm{NaCl}$, and it is also considered an antihypertensive..$^{7-11}$

Among the various salting processes is immersion in brine. The factors that most influence the salt absorption by the cheese are the gradient concentration, cheese geometry, salting time, brine temperature, and cheese moisture content. ${ }^{7,12}$ During salting, the dominant mass transport process is diffusion, due to the difference in salt concentration between the brine and the Prato cheese. ${ }^{3}$

The solute gain and water loss models are based on the fact that mass transfer can be described by Fick's diffusion law. ${ }^{13}$ In the mass transfer between the cheese and the brine, a film is formed on the surface and the salt flow must pass through this stationary resistive layer. $^{14,15}$ To assess the resistance of the film formed on the surface

*e-mail: dborsato@uel.br and the factors that interfere with the diffusion, some data analysis tools, which employ unconventional statistics, can be used..$^{15,16}$

Two of these tools are the multi-layer perceptron (MLP) and self-organizing map (SOM) artificial neural networks (ANN) used for modeling and classifying samples. ${ }^{17}$ They have been applied to solve various types of problems in different areas of science, such as engineering, medicine, chemistry, bioenergy, etc. ${ }^{17-21}$ The MLP uses the error-correction learning rule, performing training in a supervised way, applying the error back-propagation algorithm. ${ }^{16}$ SOM-type networks are based on competitive learning characterized by unsupervised learning with the formation of a topological map of input patterns, which can be one- or two-dimensional. ${ }^{16,22}$

The objective of this work was to investigate the formation, influence, and behavior of the film during multicomponent diffusion of $\mathrm{NaCl}$ and $\mathrm{KCl}$, in static and dynamic brine of Prato cheese, applying ANN (MLP and SOM) with 3D computational modeling, using the Finite Element Method (FEM).

\section{EXPERIMENTAL PART}

\section{Prato cheese}

It was used $3 \mathrm{~kg}$ of Prato cheese with rectangular geometry, provided by Laticínios Campina Alta (Manoel Ribas, Paraná - Brazil). The cheese was divided into standardized geometry samples of $0.04 \mathrm{~m} \times 0.04 \mathrm{~m} \times 0.02 \mathrm{~m}$ (Figure 1).

\section{Prato cheese brine}

A solution containing $15 \mathrm{~L}$ of brine with $5 \%$ (mass/volume) of salts was prepared. The salt composition was divided into $30 \%$ of $\mathrm{KCl}(\mathrm{KCl}$, Synth, Diadema, Brazil) and $70 \%$ of $\mathrm{NaCl}(\mathrm{NaCl}$, Panreac, Barcelona, Spain), according to Borsato et al. ${ }^{23}$ The samples were arranged in a holder, composed of nylon wires, and submerged since the Prato cheese was denser than the brine. The diffusion processes were performed in stirred and dynamic brine, the latter 
with a solution flow of $520 \mathrm{~L} \mathrm{~h}^{-1}$, at a constant temperature of $20{ }^{\circ} \mathrm{C}$ $\left( \pm 1{ }^{\circ} \mathrm{C}\right)$, according to Bordin et al. ${ }^{9}$

\section{Determination of sodium and potassium chloride}

The concentration of sodium and potassium chloride in the Prato cheese samples was measured according to Bordin et al.,${ }^{9}$ with modifications, using the Micronal photometer, model B-462 (São Paulo, Brazil, Micronal), with an air pressure of $0.8 \mathrm{kgf} \mathrm{cm}^{-2}$ and $1.5 \mathrm{kgf} \mathrm{cm}^{-2}$ air pump pressure, using butane gas.

\section{Finite element method simulation}

The simulation was performed using the COMSOL Multiphysics software version 5.2 (COMSOL, Inc., Burlington, MA). ${ }^{24}$ The parameters used in the simulation were: main coefficients $\left(D_{11 \mathrm{NaCl}}=0.50 \times 10^{-9} \mathrm{~m}^{2} \mathrm{~s}^{-1}\right.$ and $\left.\mathrm{D}_{22 \mathrm{KCl}}=0.30 \times 10^{-9} \mathrm{~m}^{2} \mathrm{~s}^{-1}\right)$, cross diffusion coefficients $\left(D_{12 \mathrm{NaCl}}=1.27 \times 10^{-10} \mathrm{~m}^{2} \mathrm{~s}^{-1}\right.$ and $\left.\mathrm{D}_{21 \mathrm{KCl}}=0.70 \times 10^{-10} \mathrm{~m}^{2} \mathrm{~s}^{-1}\right)$, mass transfer coefficients for static brine $\left(\mathrm{h}_{\mathrm{NaCl}}=5.14 \times 10^{-7} \mathrm{~m} \mathrm{~s}^{-1}\right.$ and $\left.\mathrm{h}_{\mathrm{KCl}}=3.1010^{-7} \mathrm{~m} \mathrm{~s}^{-1}\right)$ and mass transfer coefficients for dynamic brine $\left(\mathrm{h}_{\mathrm{NaCl}}=2.1010^{-6} \mathrm{~m} \mathrm{~s}^{-1}\right.$ and $\left.\mathrm{h}_{\mathrm{KCl}}=1.26 \times 10^{-6} \mathrm{~m} \mathrm{~s}^{-1}\right){ }^{8,15}$ In the simulation, salting times ranged from 0 to 28 hours.

Figure 1 presents the solid generated automatically by the software, showing part of the tetrahedral mesh used, and the equidistant points chosen for the study of $\mathrm{NaCl}$ and $\mathrm{KCl}$ diffusion on the surface of the film formed in the Prato cheese.

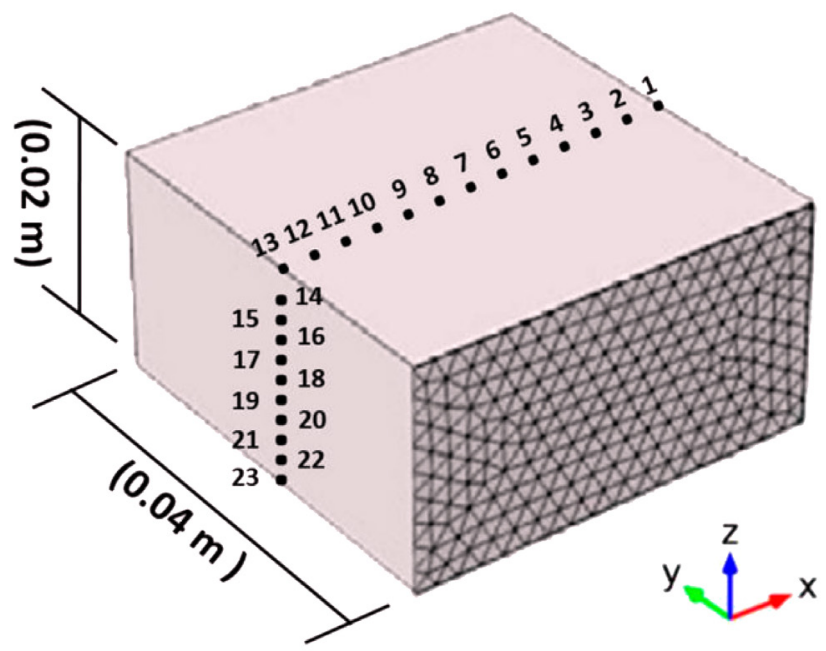

Figure 1. Solid automatically generated by the software and the positions used in the simulation

\section{Artificial Neural Networks}

The self-organizing map (SOM) proposed by Kohonen ${ }^{22}$ was used to evaluate the influence and behavior of $\mathrm{NaCl}$ and $\mathrm{KCl}$ concentrations in the Prato cheese surface. The neural network routine developed by our research group was applied according to the algorithm described by Haykin ${ }^{16}$ and processed in the Matlab ${ }^{\circledR}$ R2007b software. ${ }^{25}$

For the salting time modeling, the multilayer perceptron network (MLP) of the artificial neural network module of the Statistica $13.4^{26}$ software was used. The salting time (hours) was chosen as the continuous target variable, the salt concentrations (g $100^{-1} \mathrm{~g}$ of solution) at points P1-P7 and P13-P18 (Figure 1) were selected as dependent variables, and the static $(Z=1)$ and dynamic $(Z=2)$ system were chosen as categorical variables.
For the network MLP training, 200 epochs, a learning rate of 0.05 , and a random subdivision of the samples were used, in three groups: $70 \%$ for training, $15 \%$ for testing, and $15 \%$ for validation. ${ }^{16,26}$

The algorithms used for activating the hidden layer and the output were selected by the application among those that make up its library for the module used, that is, identity, logistic (logistic sigmoid), hyperbolic tangent, sine, and exponential. ${ }^{26}$

\section{RESULTS AND DISCUSSION}

Samples of Prato cheese (Figure 1) were subjected to a diffusion process in brine containing $\mathrm{NaCl}$ and $\mathrm{KCl}$, with and without stirring. Samples were collected at different times varying from 0 to 28 hours and the salt concentrations, diffusion coefficients, and film coefficients were determined.

Applying the physicochemical parameters obtained, diffusion simulations were performed by the finite element method (FEM) to determine the salts concentrations on the cheese surface.

Tables 1 and 2 show the values of times (h) and $\mathrm{NaCl}$ and $\mathrm{KCl}$ concentrations, respectively, in $\mathrm{g} 100^{-1} \mathrm{~g}$ of solution, on the surface of Prato cheese during the simulation of the immersion salting process using static $(\mathrm{Z}=1)$ and dynamic $(\mathrm{Z}=2)$ brine.

The concentration at $\mathrm{P} 1$ and $\mathrm{P} 13$ are the same because they are at the same point (Figure 1). During the diffusion process, the concentration values at each point increase being higher at the extremities (P1 and P13) and lower at the center of the surface and in the cheese's sides (P7 and P18). As expected, at the same salting points and times, the concentration values are higher when using brine with stirring.

As the concentration of $\mathrm{NaCl}$ and $\mathrm{KCl}$ in the initial brine is $70 \%$ and $30 \%$, respectively, the values observed for $\mathrm{NaCl}$ on the cheese surface are higher than those of $\mathrm{KCl}$. Furthermore, equilibrium concentrations are reached more quickly when using stirred brine due to the smaller influence of the physical barrier of the film that is formed on the cheese surface during salting by immersion.

To analyze the influence and behavior of the film at the chosen points (Figure 1), the data in Tables 1 and 2 were processed using the SOM-type ANN routine, inserted in the Matlab ${ }^{\circledR}$ R2007b software ${ }^{25}$ to obtain the topological maps. The applied network presented a $5 \mathrm{x}$ 5 hexagonal topology with 8000 training epochs, with learning rate training starting at 0.2 and exponentially decaying with the training epochs to $6.71 \times 10^{-5}$, and with the initial neighborhood relation of 3.5 decaying to 0.045 .

Figure 2 shows the topological maps for the points located on the upper and side cheese surfaces (Figure 1), during the multicomponent diffusion process of $\mathrm{NaCl}$ and $\mathrm{KCl}$ in static and dynamic systems. The map describes the similarity of the points as a function of the neurons-distances (hexagons) in which they are located. For both salts and systems, points P1 and P13 are on the same neuron, indicating that they have the same diffusion behavior over time. The same happens with points $\mathrm{P} 6$ and $\mathrm{P} 7$, and $\mathrm{P} 17$ and $\mathrm{P} 18$ except for $\mathrm{KCl}$ in the dynamic system.

Furthermore, the points classified into neighboring neurons, surrounded in Figure 2, are part of the same group, which means that they present similarity in terms of concentration variation. According to Figure 2, it is possible to observe the formation of 4 groups for both salts and systems. One of them is formed by points P1 and P13, which are similar points located on the edges of the faces. These are also the points that present the highest concentrations of salts, because due to their position they are exposed to a greater number of shocks and, consequently, greater diffusion speed. A second group is formed by points from P4 to $\mathrm{P} 7$ and a third one is formed by points from P15 to P18 plus P3. 
Table 1. Salting time and concentration in $\mathrm{x}$ and $\mathrm{z}$-axis positions (Figure 1) studied for $\mathrm{NaCl}$ diffusion in Prato cheese

\begin{tabular}{|c|c|c|c|c|c|c|c|c|c|c|c|c|c|c|}
\hline \multirow{3}{*}{$\mathrm{Z}$} & \multirow{3}{*}{ Time (h) } & \multicolumn{7}{|c|}{$\mathrm{x}$-axis } & \multicolumn{6}{|c|}{$\mathrm{z}$-axis } \\
\hline & & $\mathrm{P} 1$ & $\mathrm{P} 2$ & P3 & P4 & P5 & P6 & $\mathrm{P} 7$ & $\mathrm{P} 13$ & $\mathrm{P} 14$ & $\mathrm{P} 15$ & P16 & $\mathrm{P} 17$ & P18 \\
\hline & & \multicolumn{13}{|c|}{ Static system $\left(\mathrm{g} \mathrm{100^{-1 } \mathrm { g } )}\right.$} \\
\hline 1 & 0.25 & 2.78 & 1.89 & 1.90 & 1.88 & 1.89 & 1.90 & 1.89 & 2.78 & 1.89 & 1.89 & 1.89 & 1.88 & 1.89 \\
\hline 1 & 0.42 & 2.98 & 2.12 & 2.13 & 2.12 & 2.13 & 2.13 & 2.12 & 2.98 & 2.18 & 2.12 & 2.12 & 2.12 & 2.12 \\
\hline 1 & 0.50 & 3.04 & 2.21 & 2.21 & 2.20 & 2.21 & 2.21 & 2.21 & 3.04 & 2.28 & 2.21 & 2.21 & 2.20 & 2.20 \\
\hline 1 & 0.58 & 3.09 & 2.28 & 2.28 & 2.27 & 2.28 & 2.28 & 2.27 & 3.09 & 2.37 & 2.27 & 2.27 & 2.27 & 2.27 \\
\hline 1 & 0.75 & 3.16 & 2.40 & 2.38 & 2.38 & 2.38 & 2.38 & 2.38 & 3.16 & 2.51 & 2.39 & 2.38 & 2.38 & 2.38 \\
\hline 1 & 1.00 & 3.23 & 2.54 & 2.50 & 2.49 & 2.50 & 2.50 & 2.50 & 3.23 & 2.67 & 2.51 & 2.50 & 2.50 & 2.50 \\
\hline 1 & 1.50 & 3.30 & 2.72 & 2.65 & 2.65 & 2.65 & 2.65 & 2.65 & 3.31 & 2.87 & 2.69 & 2.65 & 2.65 & 2.65 \\
\hline 1 & 2.00 & 3.35 & 2.85 & 2.75 & 2.75 & 2.75 & 2.75 & 2.75 & 3.35 & 2.99 & 2.81 & 2.76 & 2.75 & 2.75 \\
\hline 1 & 2.50 & 3.37 & 2.94 & 2.83 & 2.82 & 2.82 & 2.82 & 2.82 & 3.37 & 3.07 & 2.90 & 2.84 & 2.82 & 2.82 \\
\hline 1 & 4.50 & 3.43 & 3.14 & 3.02 & 2.98 & 2.98 & 2.98 & 2.98 & 3.43 & 3.24 & 3.11 & 3.03 & 3.00 & 2.99 \\
\hline 1 & 5.00 & 3.43 & 3.17 & 3.05 & 3.01 & 3.00 & 3.00 & 3.00 & 3.43 & 3.26 & 3.14 & 3.07 & 3.03 & 3.02 \\
\hline 1 & 6.00 & 3.44 & 3.22 & 3.10 & 3.05 & 3.04 & 3.04 & 3.04 & 3.44 & 3.30 & 3.19 & 3.12 & 3.08 & 3.07 \\
\hline 1 & 7.50 & 3.45 & 3.27 & 3.16 & 3.11 & 3.09 & 3.09 & 3.09 & 3.45 & 3.34 & 3.24 & 3.18 & 3.14 & 3.13 \\
\hline 1 & 15.00 & 3.48 & 3.38 & 3.31 & 3.26 & 3.24 & 3.23 & 3.22 & 3.48 & 3.42 & 3.37 & 3.33 & 3.31 & 3.30 \\
\hline 1 & 18.00 & 3.48 & 3.41 & 3.35 & 3.30 & 3.28 & 3.27 & 3.26 & 3.48 & 3.44 & 3.40 & 3.37 & 3.35 & 3.34 \\
\hline 1 & 24.00 & 3.49 & 3.44 & 3.40 & 3.37 & 3.34 & 3.33 & 3.33 & 3.49 & 3.46 & 3.43 & 3.41 & 3.40 & 3.40 \\
\hline \multirow[t]{2}{*}{1} & 28.00 & 3.49 & 3.45 & 3.42 & 3.40 & 3.38 & 3.37 & 3.36 & 3.49 & 3.47 & 3.45 & 3.43 & 3.43 & 3.42 \\
\hline & & \multicolumn{13}{|c|}{ Dynamic system $\left(\mathrm{g} \mathrm{100}^{1} \mathrm{~g}\right)$} \\
\hline 2 & 0.250 & 3.49 & 2.97 & 2.97 & 2.96 & 2.97 & 2.97 & 2.97 & 3.48 & 2.97 & 2.96 & 2.97 & 2.96 & 2.97 \\
\hline 2 & 0.42 & 3.50 & 3.08 & 3.08 & 3.07 & 3.08 & 3.08 & 3.08 & 3.49 & 3.11 & 3.08 & 3.08 & 3.08 & 3.08 \\
\hline 2 & 0.50 & 3.50 & 3.11 & 3.11 & 3.11 & 3.11 & 3.11 & 3.11 & 3.50 & 3.15 & 3.11 & 3.11 & 3.11 & 3.11 \\
\hline 2 & 0.58 & 3.50 & 3.14 & 3.14 & 3.14 & 3.14 & 3.14 & 3.14 & 3.50 & 3.19 & 3.14 & 3.14 & 3.14 & 3.14 \\
\hline 2 & 0.75 & 3.50 & 3.19 & 3.18 & 3.18 & 3.18 & 3.18 & 3.18 & 3.50 & 3.24 & 3.18 & 3.18 & 3.18 & 3.18 \\
\hline 2 & 1.00 & 3.50 & 3.24 & 3.22 & 3.22 & 3.22 & 3.22 & 3.22 & 3.50 & 3.29 & 3.23 & 3.22 & 3.22 & 3.22 \\
\hline 2 & 1.50 & 3.50 & 3.30 & 3.27 & 3.27 & 3.27 & 3.27 & 3.27 & 3.50 & 3.35 & 3.29 & 3.27 & 3.27 & 3.27 \\
\hline 2 & 2.00 & 3.50 & 3.34 & 3.30 & 3.30 & 3.30 & 3.30 & 3.30 & 3.50 & 3.39 & 3.33 & 3.31 & 3.30 & 3.30 \\
\hline 2 & 2.50 & 3.50 & 3.37 & 3.33 & 3.32 & 3.32 & 3.32 & 3.32 & 3.50 & 3.41 & 3.35 & 3.33 & 3.32 & 3.32 \\
\hline 2 & 4.50 & 3.50 & 3.42 & 3.38 & 3.37 & 3.37 & 3.37 & 3.37 & 3.50 & 3.45 & 3.41 & 3.39 & 3.37 & 3.37 \\
\hline 2 & 5.00 & 3.50 & 3.43 & 3.39 & 3.38 & 3.37 & 3.37 & 3.37 & 3.50 & 3.45 & 3.42 & 3.39 & 3.38 & 3.38 \\
\hline 2 & 6.00 & 3.50 & 3.44 & 3.40 & 3.39 & 3.39 & 3.39 & 3.39 & 3.50 & 3.46 & 3.43 & 3.41 & 3.40 & 3.39 \\
\hline 2 & 7.50 & 3.50 & 3.45 & 3.42 & 3.40 & 3.40 & 3.40 & 3.40 & 3.50 & 3.47 & 3.44 & 3.42 & 3.41 & 3.41 \\
\hline 2 & 15.00 & 3.50 & 3.48 & 3.46 & 3.44 & 3.44 & 3.43 & 3.43 & 3.50 & 3.48 & 3.47 & 3.46 & 3.46 & 3.45 \\
\hline 2 & 18.00 & 3.50 & 3.48 & 3.47 & 3.45 & 3.45 & 3.45 & 3.44 & 3.50 & 3.49 & 3.48 & 3.47 & 3.47 & 3.46 \\
\hline
\end{tabular}

In the two cases, P2 is included. Nevertheless, in the two cases where P2 was not part of this third group, it is located close to it, still indicating a certain behavior similarity. Point P14 makes up the fourth and last group, but it is located close to the third group in all cases, indicating, as well as P2, a certain behavior similarity.

With these results, it can be concluded that the points that occupy similar positions concerning the distance from the edge present similar behavior. It is important to note that the side and surface have different lengths, so the spacing of the points is in different scales (Figure 1).

For this reason, the points in the center of the upper face (group 2 ), were not classified as the same group of the side face center (group 4). A more detailed analysis shows that points P6 and P7, which do not have equivalents on the lateral face, are furthest from the points of group 3. On the other hand, $\mathrm{P} 4$ is part of group 2 but is closer to the samples of group 3, which corroborates the direct dependence of diffusion to the distance with the solid edge suggested above.
To model the diffusion of sodium chloride and potassium chloride on the Prato cheese surface during the salting process, using static and dynamic brine, the values presented in Tables 1 and 2 were tabulated and presented to the neural network regression module of Statistica software $13.4 .{ }^{26}$

In the regression module, the multilayer perceptron neural network (MLP) was used, testing 5 to 20 hidden layers. The networks were trained with $70 \%$ of the samples for the training group, $15 \%$ for testing, and $15 \%$ for validation. The choice of samples in each group was performed randomly to avoid that the successive examples presented to the network at an epoch, rarely belong to the same class. ${ }^{16}$ The test and validation stages aim to verify the ability of the trained network to perform generalizations. ${ }^{16,17,27}$

In the MLP modeling, 200 networks were trained and the 5 best ones were selected by the software used. The most recommended and applied algorithm to train neural networks is the BFGS, individually 
Table 2. Salting time and concentration in $\mathrm{x}$ and $\mathrm{z}$-axis positions studied for $\mathrm{KCl}$ diffusion in Prato cheese

\begin{tabular}{|c|c|c|c|c|c|c|c|c|c|c|c|c|c|c|}
\hline \multirow{3}{*}{$\mathrm{Z}$} & \multirow{3}{*}{ Time (h) } & \multicolumn{7}{|c|}{$\mathrm{x}$-axis } & \multicolumn{6}{|c|}{$\mathrm{z}$-axis } \\
\hline & & $\mathrm{P} 1$ & $\mathrm{P} 2$ & $\mathrm{P} 3$ & $\mathrm{P} 4$ & P5 & P6 & $\mathrm{P} 7$ & $\mathrm{P} 13$ & $\mathrm{P} 14$ & $\mathrm{P} 15$ & $\mathrm{P} 16$ & $\mathrm{P} 17$ & $\mathrm{P} 18$ \\
\hline & & \multicolumn{13}{|c|}{ Static system $\left(\mathrm{g} \mathrm{100^{-1 } \mathrm { g } )}\right.$} \\
\hline 1 & 0.25 & 1.05 & 0.74 & 0.75 & 0.74 & 0.75 & 0.75 & 0.75 & 1.05 & 0.75 & 0.75 & 0.75 & 0.74 & 0.75 \\
\hline 1 & 0.42 & 1.16 & 0.83 & 0.83 & 0.83 & 0.83 & 0.83 & 0.83 & 1.16 & 0.85 & 0.83 & 0.83 & 0.83 & 0.83 \\
\hline 1 & 0.50 & 1.19 & 0.86 & 0.87 & 0.86 & 0.87 & 0.87 & 0.86 & 1.19 & 0.89 & 0.86 & 0.86 & 0.86 & 0.86 \\
\hline 1 & 0.58 & 1.22 & 0.89 & 0.89 & 0.89 & 0.89 & 0.89 & 0.89 & 1.22 & 0.93 & 0.89 & 0.89 & 0.89 & 0.89 \\
\hline 1 & 0.75 & 1.26 & 0.94 & 0.94 & 0.93 & 0.94 & 0.94 & 0.93 & 1.26 & 0.99 & 0.94 & 0.93 & 0.93 & 0.93 \\
\hline 1 & 1.00 & 1.31 & 1.00 & 0.99 & 0.98 & 0.99 & 0.99 & 0.98 & 1.31 & 1.06 & 0.99 & 0.98 & 0.98 & 0.98 \\
\hline 1 & 1.50 & 1.36 & 1.08 & 1.05 & 1.05 & 1.05 & 1.05 & 1.05 & 1.36 & 1.15 & 1.07 & 1.05 & 1.05 & 1.05 \\
\hline 1 & 2.00 & 1.39 & 1.14 & 1.10 & 1.10 & 1.10 & 1.10 & 1.10 & 1.39 & 1.21 & 1.13 & 1.10 & 1.10 & 1.10 \\
\hline 1 & 2.50 & 1.41 & 1.19 & 1.14 & 1.13 & 1.13 & 1.13 & 1.13 & 1.41 & 1.25 & 1.17 & 1.14 & 1.13 & 1.13 \\
\hline 1 & 4.50 & 1.44 & 1.29 & 1.23 & 1.22 & 1.21 & 1.21 & 1.21 & 1.44 & 1.34 & 1.28 & 1.24 & 1.22 & 1.22 \\
\hline 1 & 5.00 & 1.45 & 1.31 & 1.25 & 1.23 & 1.23 & 1.23 & 1.23 & 1.45 & 1.35 & 1.29 & 1.26 & 1.24 & 1.23 \\
\hline 1 & 6.00 & 1.46 & 1.33 & 1.27 & 1.25 & 1.25 & 1.25 & 1.25 & 1.46 & 1.38 & 1.32 & 1.28 & 1.26 & 1.26 \\
\hline 1 & 7.50 & 1.46 & 1.36 & 1.30 & 1.28 & 1.27 & 1.27 & 1.27 & 1.47 & 1.40 & 1.35 & 1.31 & 1.30 & 1.29 \\
\hline 1 & 15.00 & 1.48 & 1.43 & 1.39 & 1.36 & 1.35 & 1.34 & 1.34 & 1.48 & 1.45 & 1.42 & 1.40 & 1.39 & 1.38 \\
\hline 1 & 18.00 & 1.49 & 1.44 & 1.41 & 1.38 & 1.37 & 1.37 & 1.36 & 1.49 & 1.46 & 1.43 & 1.42 & 1.41 & 1.40 \\
\hline 1 & 24.00 & 1.49 & 1.46 & 1.44 & 1.42 & 1.41 & 1.40 & 1.40 & 1.49 & 1.47 & 1.46 & 1.44 & 1.44 & 1.43 \\
\hline \multirow[t]{2}{*}{1} & 28.00 & 1.49 & 1.47 & 1.45 & 1.43 & 1.42 & 1.42 & 1.42 & 1.49 & 1.48 & 1.47 & 1.46 & 1.45 & 1.45 \\
\hline & & \multicolumn{13}{|c|}{ Dynamic system $\left(\mathrm{g} \mathrm{100}^{-1} \mathrm{~g}\right)$} \\
\hline 2 & 0.25 & 1.47 & 1.21 & 1.21 & 1.20 & 1.21 & 1.21 & 1.21 & 1.47 & 1.21 & 1.21 & 1.21 & 1.21 & 1.21 \\
\hline 2 & 0.42 & 1.48 & 1.27 & 1.27 & 1.26 & 1.27 & 1.27 & 1.27 & 1.48 & 1.28 & 1.27 & 1.27 & 1.27 & 1.27 \\
\hline 2 & 0.50 & 1.49 & 1.29 & 1.29 & 1.28 & 1.29 & 1.29 & 1.28 & 1.49 & 1.30 & 1.28 & 1.28 & 1.28 & 1.28 \\
\hline 2 & 0.58 & 1.49 & 1.30 & 1.30 & 1.30 & 1.30 & 1.30 & 1.30 & 1.49 & 1.32 & 1.30 & 1.30 & 1.30 & 1.30 \\
\hline 2 & 0.75 & 1.49 & 1.33 & 1.32 & 1.32 & 1.32 & 1.32 & 1.32 & 1.49 & 1.35 & 1.32 & 1.32 & 1.32 & 1.32 \\
\hline 2 & 1.00 & 1.49 & 1.35 & 1.34 & 1.34 & 1.34 & 1.34 & 1.34 & 1.49 & 1.38 & 1.35 & 1.34 & 1.34 & 1.34 \\
\hline 2 & 1.50 & 1.50 & 1.39 & 1.37 & 1.37 & 1.37 & 1.37 & 1.37 & 1.50 & 1.41 & 1.38 & 1.37 & 1.37 & 1.37 \\
\hline 2 & 2.00 & 1.50 & 1.41 & 1.39 & 1.39 & 1.39 & 1.39 & 1.39 & 1.50 & 1.43 & 1.40 & 1.39 & 1.39 & 1.39 \\
\hline 2 & $2.5^{\circ}$ & 1.50 & 1.42 & 1.40 & 1.40 & 1.40 & 1.40 & 1.40 & 1.50 & 1.44 & 1.42 & 1.40 & 1.40 & 1.40 \\
\hline 2 & 4.50 & 1.50 & 1.45 & 1.43 & 1.43 & 1.43 & 1.43 & 1.43 & 1.50 & 1.47 & 1.45 & 1.43 & 1.43 & 1.43 \\
\hline 2 & 5.00 & 1.50 & 1.46 & 1.44 & 1.43 & 1.43 & 1.43 & 1.43 & 1.50 & 1.47 & 1.45 & 1.44 & 1.43 & 1.43 \\
\hline 2 & 6.00 & 1.50 & 1.46 & 1.44 & 1.44 & 1.44 & 1.44 & 1.44 & 1.50 & 1.48 & 1.46 & 1.45 & 1.44 & 1.44 \\
\hline 2 & 7.50 & 1.50 & 1.47 & 1.45 & 1.44 & 1.44 & 1.44 & 1.44 & 1.50 & 1.48 & 1.47 & 1.46 & 1.45 & 1.45 \\
\hline 2 & 15.00 & 1.50 & 1.49 & 1.47 & 1.47 & 1.46 & 1.46 & 1.46 & 1.50 & 1.49 & 1.48 & 1.48 & 1.47 & 1.47 \\
\hline 2 & 18.00 & 1.50 & 1.49 & 1.48 & 1.47 & 1.47 & 1.47 & 1.47 & 1.50 & 1.49 & 1.49 & 1.48 & 1.48 & 1.48 \\
\hline 2 & 24.00 & 1.50 & 1.49 & 1.49 & 1.48 & 1.48 & 1.48 & 1.48 & 1.50 & 1.50 & 1.49 & 1.49 & 1.49 & 1.49 \\
\hline
\end{tabular}

proposed by Broyden-Fletcher-Goldfarb-Shanno. ${ }^{27}$ This method has a better performance than more traditional algorithms such as the gradient method, but it uses more memory and requires more computational time. However, this technique may require fewer iterations to train a neural network due to its fast convergence rate. ${ }^{16,27}$ Before starting the MLP network, the BFGS algorithms and the sum-of-squares (SOS) error function were selected, which is the most suitable for regression problems. ${ }^{28}$ In addition, a learning rate of 0.05 was applied with a maximum number of epochs equal to 200 . The strategy to create the predictive model was to use the automated network search of the Statistica 13.4 software. $^{26}$

Figure 3 provides a general indication of how training and testing are progressing. It shows the number of epochs used to train and test the network with the best performance, revealing that the network needed only 20 epochs to reach training stability for the $\mathrm{NaCl}$ concentration data, and 156 epochs to train the network with $\mathrm{KCl}$ concentration data on the cheese surface. Before error stabilization an oscillation was also observed, being greater for the $\mathrm{NaCl}$ data.

Table 3 shows the 5 networks selected by the software for modeling each salting component, the performance of training, test, and validation. The BFGS and SOS algorithms were fixed and the others were chosen by the automatic module of the Statistica software. $^{26}$

Sensitivity analysis of the data allows the assessment of the contribution of each independent variable in the construction of the predictive model. Thus, considering the 5 trained networks chosen as the best, it was possible to stipulate an order of importance for each input variable in the general model adjustment. Table 4 shows the importance of each parameter, in percentage, obtained from the 

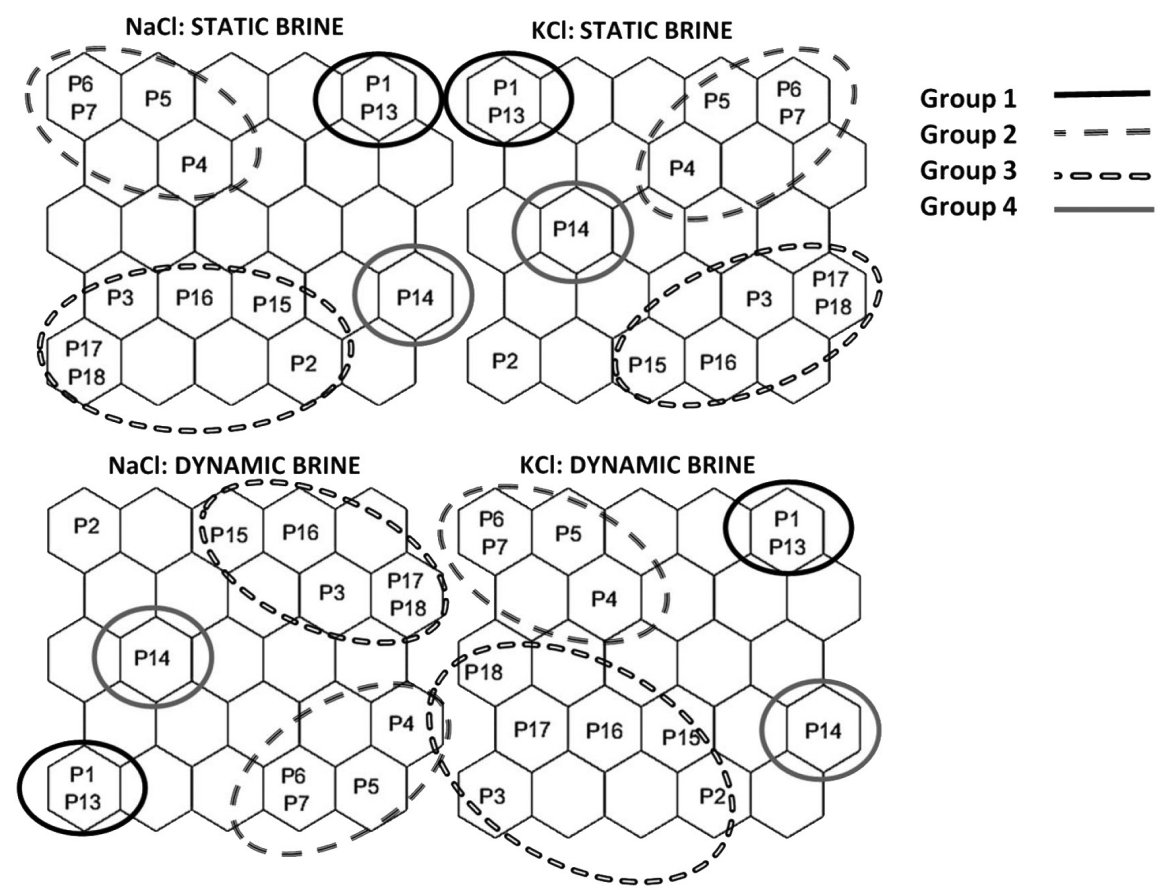

Figure 2. Topological maps for the diffusion of $\mathrm{NaCl}$ and $\mathrm{KCl}$
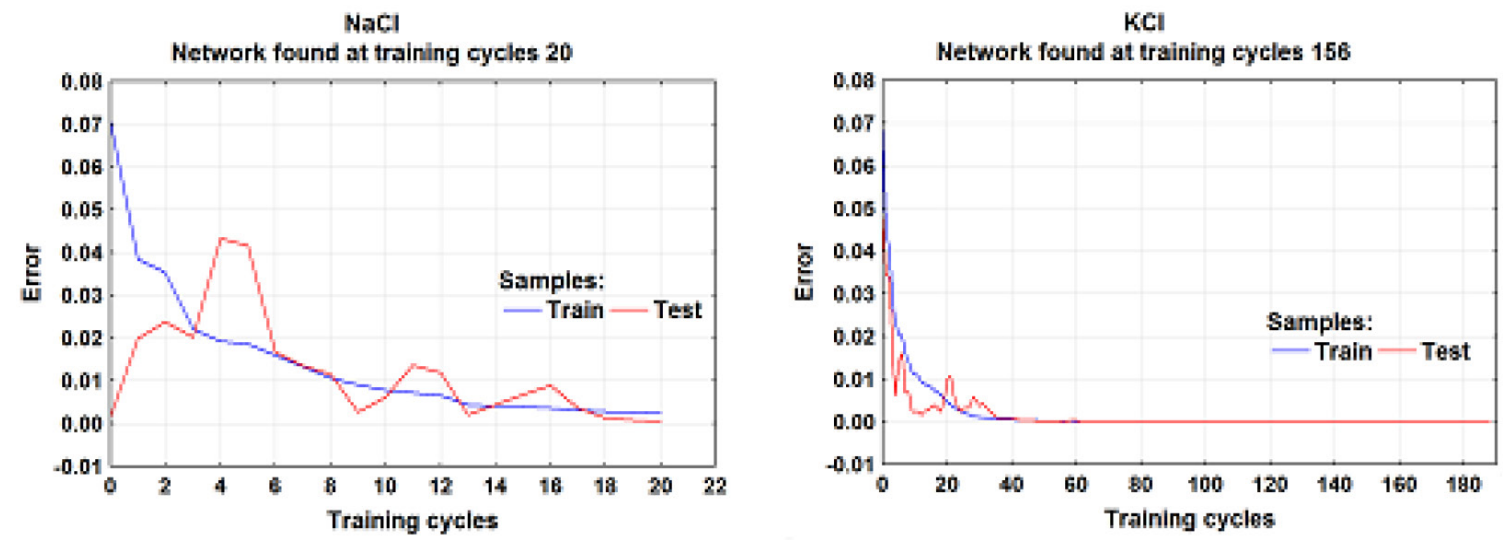

Figure 3. Error stabilization and the number of epochs used for the network train and test of $\mathrm{NaCl}$ and $\mathrm{KCl}$

Table 3. Summary of active networks for $\mathrm{NaCl}$ and $\mathrm{KCl}$ data

\begin{tabular}{|c|c|c|c|c|c|c|c|}
\hline MLP Name & $\begin{array}{c}\text { Training } \\
\text { Perf. }\end{array}$ & $\begin{array}{l}\text { Test } \\
\text { Perf. }\end{array}$ & $\begin{array}{l}\text { Validation } \\
\text { Perf. }\end{array}$ & $\begin{array}{c}\text { Training } \\
\text { Algorithm }\end{array}$ & $\begin{array}{c}\text { Error } \\
\text { Function }\end{array}$ & $\begin{array}{c}\text { Hidden } \\
\text { Activation }\end{array}$ & $\begin{array}{c}\text { Output } \\
\text { Activation }\end{array}$ \\
\hline \multicolumn{8}{|c|}{ Active networks for $\mathrm{NaCl}$ diffusion } \\
\hline $15-19-1$ & 0.999 & 0.999 & 0.999 & BFGS & SOS & Exponential & Exponential \\
\hline $15-14-1$ & 0.999 & 0.999 & 1.000 & BFGS & SOS & Tanh & Logistic \\
\hline $15-8-1$ & 0.999 & 0.999 & 1.000 & BFGS & SOS & Logistic & Logistic \\
\hline $15-14-1$ & 0.999 & 0.999 & 1.000 & BFGS & SOS & Exponential & Exponential \\
\hline $15-15-1$ & 0.999 & 0.999 & 1.000 & BFGS & SOS & Exponential & Exponential \\
\hline \multicolumn{8}{|c|}{ Active networks for $\mathrm{KCl}$ diffusion } \\
\hline $15-5-1$ & 0.999 & 1.000 & 1.000 & BFGS & SOS & Tanh & Identity \\
\hline $15-14-1$ & 0.999 & 1.000 & 0.999 & BFGS & SOS & Exponential & Exponential \\
\hline $15-19-1$ & 0.999 & 0.999 & 0.999 & BFGS & SOS & Tanh & Exponential \\
\hline $15-7-1$ & 0.999 & 1.000 & 0.999 & BFGS & SOS & Exponential & Exponential \\
\hline $15-19-1$ & 0.999 & 1.000 & 0.999 & BFGS & SOS & Exponential & Exponential \\
\hline
\end{tabular}

average value of each network used. The most important parameters in the construction of the model to estimate the salting time of $\mathrm{NaCl}$ were $\mathrm{P} 14>\mathrm{Z}>\mathrm{P} 1>\mathrm{P} 13>\mathrm{P} 2$ and for the $\mathrm{KCl}$ model was $\mathrm{P} 14>\mathrm{Z}>\mathrm{P} 2$.

The performance of neural networks is measured by their ability to predict unseen data, that is, values that were not used during training. Thus, test samples randomly chosen by the software were used to verify the performance of the model and its generalization ability. To avoid just a coincidence of test results, a set of unseen validation data was used as well as an extra verification of the model's performance..$^{16,27,28}$ 
Table 4. Sensitivity analysis of the parameters used by the models for the samples chosen for training, test, and validation

\begin{tabular}{|c|c|c|c|c|c|c|c|c|c|c|c|c|c|}
\hline \multicolumn{14}{|c|}{$\mathrm{NaCl}$ model (\%) } \\
\hline P14 & $\mathrm{Z}$ & $\mathrm{P} 1$ & P13 & $\mathrm{P} 2$ & $\mathrm{P} 15$ & P18 & P7 & P6 & P5 & P17 & $\mathrm{P} 4$ & P3 & $\mathrm{P} 16$ \\
\hline 32.78 & 17.07 & 12.50 & 11.92 & 8.80 & 2.97 & 2.37 & 2.23 & 2.17 & 1.87 & 1.71 & 1.67 & 0.98 & 0.95 \\
\hline \multicolumn{14}{|c|}{ KCl model (\%) } \\
\hline P14 & $\mathrm{Z}$ & $\mathrm{P} 2$ & $\mathrm{P} 13$ & $\mathrm{P} 1$ & P5 & P6 & P7 & $\mathrm{P} 4$ & P18 & P17 & P3 & P15 & P16 \\
\hline 76.80 & 7.45 & 4.66 & 2.27 & 2.14 & 1.14 & 1.12 & 1.01 & 0.77 & 0.70 & 0.60 & 0.54 & 0.44 & 0.35 \\
\hline
\end{tabular}

According to Tables 5 and 6, the Tukey test showed no significant difference, at the $5 \%$ level, between the averages of the times obtained by the 5 networks with the best performance for $\mathrm{NaCl}$ and $\mathrm{KCl}$, showing that the model can be used for predictive purposes. Standard deviation and standard error values were low, making the statistical test very rigorous since the average values are very close to the times used in salting.
For the dependent variable (target), the variance analysis of the absolute deviation values of the respective mean times was performed using Levene's test. For all cases analyzed, the values were not significant, indicating that the hypothesis of homogeneous variances should not be rejected.

Figure 4 shows the low dispersion between predicted and experimental values of the salting time, during the training of the 5

Table 5. $\mathrm{NaCl}$ salting time in hours, mean of predicted times, standard deviation ( $\mathrm{StdD})$, standard error (StdE), p statistic of the Tukey and Levene's tests

\begin{tabular}{|c|c|c|c|c|c|c|}
\hline Sample & Time (h) & $\begin{array}{l}\text { Mean of predicted } \\
\text { times }(\mathrm{h})\end{array}$ & StdD & StdE & Tukey test & Levene's test \\
\hline \multicolumn{7}{|c|}{ Static System } \\
\hline Test & 0.250 & 0.265 & 0.023 & 0.010 & 0.625 & 0.342 \\
\hline Train & 0.417 & 0.410 & 0.028 & 0.013 & 0.844 & 0.371 \\
\hline Test & 0.500 & 0.496 & 0.009 & 0.004 & 0.682 & 0.357 \\
\hline Train & 0.583 & 0.578 & 0.017 & 0.007 & 0.784 & 0.413 \\
\hline Train & 0.750 & 0.753 & 0.027 & 0.012 & 0.914 & 0.407 \\
\hline Train & 1.000 & 1.015 & 0.022 & 0.010 & 0.562 & 0.200 \\
\hline Train & 1.500 & 1.513 & 0.017 & 0.008 & 0.516 & 0.174 \\
\hline Train & 2.000 & 2.000 & 0.002 & 0.001 & 0.964 & 0.147 \\
\hline Train & 2.500 & 2.488 & 0.012 & 0.005 & 0.403 & 0.356 \\
\hline Train & 4.500 & 4.493 & 0.011 & 0.005 & 0.588 & 0.394 \\
\hline Train & 5.000 & 5.002 & 0.005 & 0.002 & 0.696 & 0.164 \\
\hline Validation & 6.000 & 6.022 & 0.009 & 0.004 & 0.077 & 0.085 \\
\hline Train & 7.500 & 7.536 & 0.018 & 0.008 & 0.153 & 0.285 \\
\hline Train & 15.000 & 14.958 & 0.020 & 0.009 & 0.126 & 0.163 \\
\hline Train & 18.000 & 17.986 & 0.014 & 0.006 & 0.421 & 0.374 \\
\hline Train & 24.000 & 24.073 & 0.029 & 0.013 & 0.083 & 0.242 \\
\hline Train & 28.000 & 27.958 & 0.021 & 0.009 & 0.139 & 0.321 \\
\hline \multicolumn{7}{|c|}{ Dynamic System } \\
\hline Train & 0.250 & 0.289 & 0.026 & 0.012 & 0.248 & 0.347 \\
\hline Validation & 0.417 & 0.431 & 0.011 & 0.005 & 0.313 & 0.119 \\
\hline Test & 0.500 & 0.510 & 0.011 & 0.005 & 0.420 & 0.356 \\
\hline Train & 0.583 & 0.594 & 0.010 & 0.004 & 0.389 & 0.393 \\
\hline Validation & 0.750 & 0.759 & 0.013 & 0.006 & 0.539 & 0.470 \\
\hline Train & 1.000 & 1.008 & 0.012 & 0.006 & 0.573 & 0.368 \\
\hline Train & 1.500 & 1.503 & 0.008 & 0.003 & 0.706 & 0.157 \\
\hline Train & 2.000 & 1.997 & 0.012 & 0.005 & 0.831 & 0.250 \\
\hline Test & 2.500 & 2.488 & 0.012 & 0.005 & 0.417 & 0.220 \\
\hline Train & 4.500 & 4.483 & 0.006 & 0.003 & 0.063 & 0.234 \\
\hline Train & 5.000 & 4.992 & 0.005 & 0.002 & 0.168 & 0.367 \\
\hline Train & 6.000 & 6.002 & 0.011 & 0.005 & 0.860 & 0.063 \\
\hline Train & 7.500 & 7.512 & 0.015 & 0.007 & 0.488 & 0.099 \\
\hline Validation & 15.000 & 14.994 & 0.016 & 0.007 & 0.744 & 0.435 \\
\hline Train & 18.000 & 17.998 & 0.005 & 0.002 & 0.737 & 0.075 \\
\hline
\end{tabular}


Table 6. $\mathrm{KCl}$ salting time in hours, mean of predicted times, standard deviation (StdD), standard error (StdE), p statistic of the Tukey and Levene's tests

\begin{tabular}{|c|c|c|c|c|c|c|}
\hline Sample & Time (h) & $\begin{array}{l}\text { Mean of predicted } \\
\text { times }(\mathrm{h})\end{array}$ & StdD & StdE & Tukey test & Levene's test \\
\hline \multicolumn{7}{|c|}{ Static System } \\
\hline Train & 0.250 & 0.278 & 0.024 & 0.011 & 0.357 & 0.248 \\
\hline Train & 0.417 & 0.407 & 0.033 & 0.015 & 0.804 & 0.343 \\
\hline Train & 0.500 & 0.492 & 0.013 & 0.006 & 0.611 & 0.361 \\
\hline Train & 0.583 & 0.583 & 0.015 & 0.006 & 1.000 & 0.326 \\
\hline Train & 0.750 & 0.755 & 0.030 & 0.014 & 0.895 & 0.350 \\
\hline Train & 1.000 & 0.999 & 0.013 & 0.006 & 0.932 & 0.351 \\
\hline Test & 1.500 & 1.499 & 0.005 & 0.002 & 0.867 & 0.174 \\
\hline Test & 2.000 & 2.005 & 0.005 & 0.002 & 0.385 & 0.439 \\
\hline Validation & 2.500 & 2.507 & 0.006 & 0.003 & 0.351 & 0.388 \\
\hline Train & 4.500 & 4.508 & 0.011 & 0.005 & 0.530 & 0.350 \\
\hline Validation & 5.000 & 5.010 & 0.009 & 0.004 & 0.361 & 0.301 \\
\hline Validation & 6.000 & 6.011 & 0.006 & 0.003 & 0.361 & 0.368 \\
\hline Train & 7.500 & 7.509 & 0.008 & 0.004 & 0.164 & 0.084 \\
\hline Train & 15.000 & 14.964 & 0.024 & 0.011 & 0.364 & 0.450 \\
\hline Test & 18.000 & 17.989 & 0.012 & 0.005 & 0.461 & 0.397 \\
\hline Train & 24.000 & 24.056 & 0.036 & 0.016 & 0.222 & 0.390 \\
\hline Train & 28.000 & 27.969 & 0.019 & 0.009 & 0.211 & 0.344 \\
\hline \multicolumn{7}{|c|}{ Dynamic System } \\
\hline Train & 0.250 & 0.300 & 0.026 & 0.011 & 0.149 & 0.358 \\
\hline Test & 0.417 & 0.431 & 0.018 & 0.008 & 0.517 & 0.454 \\
\hline Train & 0.500 & 0.507 & 0.018 & 0.008 & 0.731 & 0.371 \\
\hline Train & 0.583 & 0.587 & 0.018 & 0.008 & 0.873 & 0.355 \\
\hline Validation & 0.750 & 0.752 & 0.016 & 0.007 & 0.900 & 0.392 \\
\hline Train & 1.000 & 1.001 & 0.011 & 0.005 & 0.912 & 0.221 \\
\hline Train & 1.500 & 1.501 & 0.008 & 0.003 & 0.955 & 0.430 \\
\hline Train & 2.000 & 1.994 & 0.016 & 0.007 & 0.745 & 0.403 \\
\hline Train & 2.500 & 2.490 & 0.020 & 0.009 & 0.683 & 0.367 \\
\hline Train & 4.500 & 4.489 & 0.016 & 0.007 & 0.571 & 0.365 \\
\hline Train & 5.000 & 4.990 & 0.012 & 0.005 & 0.469 & 0.282 \\
\hline Train & 6.000 & 6.009 & 0.010 & 0.005 & 0.450 & 0.112 \\
\hline Train & 7.500 & 7.499 & 0.010 & 0.004 & 0.941 & 0.407 \\
\hline Train & 15.000 & 14.986 & 0.023 & 0.010 & 0.612 & 0.347 \\
\hline Train & 18.000 & 18.035 & 0.025 & 0.011 & 0.266 & 0.084 \\
\hline
\end{tabular}

\section{NaCI Samples: Train}

- 1. MLP 15-19-1 $\circ$ 2. MLP 15-14-1 $\circ$ 3. MLP 15- 8 -1 $\circ$ 4. MLP 15-14-1 o 5. MLP 15-15-1 - $-Y$

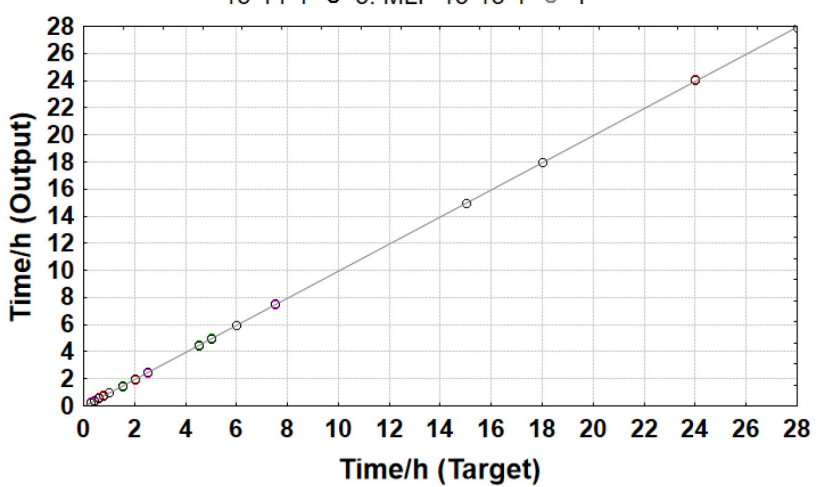

KCI Samples: Train

○ 1 MLP $15-5$-1 0 2.MLP 15-14-1 0 3.MLP 15-19-1 0 4. MLP 15$7-1$ o 5 . MLP 15-19-1- - Y

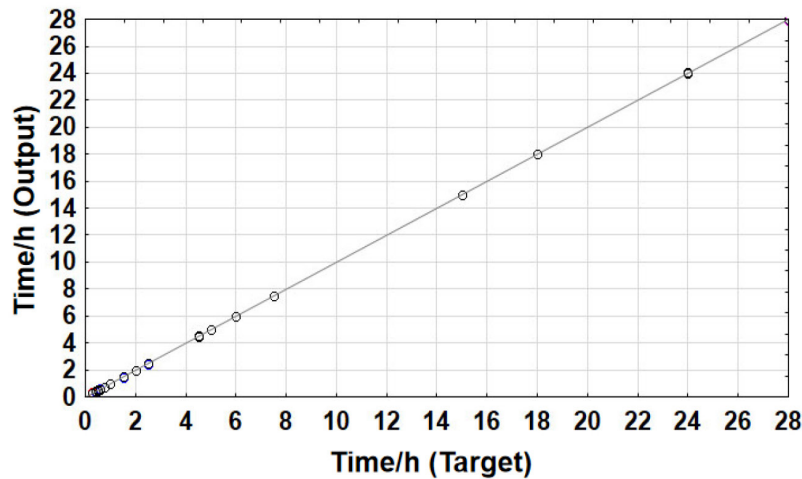

Figure 4. Dispersion graphics between predicted and experimental values for salting time and training of the top 5 networks 
best neural networks of the MLP type, which is a quality indication of the regression models.

\section{CONCLUSIONS}

In this work, the salting of Prato cheese by immersion in aqueous solution with and without stirring was studied, with partial replacement of sodium chloride by potassium salt, using computational tools such as 3D modeling by the finite element method (FEM) and neural networks of the SOM and MLP types, to evaluate the films formation on the cheese surface and to demonstrate its influence on mass transfer and diffusion time. The combination of these tools can be interesting to improve food processing techniques and help industries in cheese production.

The analysis using SOM and MLP networks showed that the film formed on the surface behaves differently during diffusion, depending on the analyzed position, and that the discrete variable $\mathrm{Z}$, which represents the agitation condition of the system, influences the time of salting. The applied statistical tests showed that the regression model that estimates the salting time can be used for predictive purposes.

\section{ACKNOWLEDGMENTS}

The authors would like to thank the State University of Londrina (UEL) and the Nacional Council for Scientific and Technological Development- CNPq.

\section{REFERENCES}

1. Delorme, M. M.; Pimentel, T. C.; Freitas, M. O.; Cubha, D. T.; Silva, R.; Guimarães, J. T.; Scudino, H; Esmerino, E. A.; Duarte, M. C. K. H.; Cruz, A. G.; Int. J. Dairy Technol. 2021, 74, 768.

2. Silva, H. L. A.; Balthazar, C. F.; Esmerino, E. A.; Cucinelli Neto, R. P.; Rocha, R. S.; Moraes, J.; Cavalcanti, R. N.; Franco, R. M.; Tavares, M. I. B.; Santos, J. S.; Granato, D.; Costa, R. G. B.; Freitas, M. Q.; Silva, M. C.; Raices, R. S. L.; Ranadheera, C. S.; Nazzaro, F.; Mortazavian, A. M.; Cruz, A. G.; Food Chem. 2018, 248, 192.

3. de Oliveira, T. F.; Clemente, M. A. J.; Galvan, D.; Fix, G.; Mantovani, A. C. G.; Moreira, I.; Andrello, A. C.; Angilelli, K. B.; Borsato, D.; Food Sci. Technol. 2020, 40, 482.

4. Bae, I.; Park, J. H.; Choi, H.Y.; Jung, H. K.; Korean Journal for Food Science of Animal Resources 2017, 37, 793.

5. Fox, P. F.; O'Connor, T. P.; Mcsweeney, P. L. H.; Guinee, T. P.; O’Brien, N. M.; 1996; pp. 163.

6. Hoffmann, W.; Luzzi, G.; Steffens, M.; Clawin-Rädecker, I.; Franz, C. M. A. P.; Fritsche, J. Int. J. Dairy Technol. 2020, 73, 270.
7. de Oliveira, T. F.; Clemente, M. A. J.; Galvan, D.; Fix, G.; Mantovani, A. C. G.; Moreira, I.; Andrello, A. C.; Angilelli, K. B.; Borsato, D.; Food Sci. Technol. 2021, 41, 375.

8. Clemente, M. A. J.; de Oliveira, T. F.; Cremasco, H.; Galvan, D.; Bordin, M. S. P.; Moreira, I.; Borsato, D.; Heat Mass Transfer 2020, 56, 2203.

9. Bordin, M. S. P.; Borsato, D.; Cremasco, H.; Galvan, D.; Silva, L. R. C.; Romagnoli, É. S.; Angilelli, K. G.; Food Chem. 2019, 273, 99.

10. Bordin, M.; Cremasco, H.; Galvan, D.; Clemente, M. A. J.; Bona, E.; Mantovanic, A. C. G.; Borsato, D.; J. Braz. Chem. Soc. 2020, 31, 1101.

11. Costa, R. G. B.; Sobral, D.; Teodoro, V. A. M.; Costa, L. C. G.; De Paula, J. C. J.; Landin, T. B.; Oliveira, M. B. LWT - Food Sci. Technol. 2018, 90, 643.

12. Gómez Salazar, J. A.; Clemente Polo, G.; Sanjuán Pelliccer, N.; Dyna 2015, 82, 23.

13. Bona, E.; Borsato, D.; Silva, R. S. dos S. F.; Silva, L. H. M.; Food Sci. 2005, 25, 394.

14. Angilelli, K. G.; Orives, J. R.; da Silva, H. C.; Coppo, R. L.; Moreira, I.; Borsato, D.; J. Food Process. Preserv. 2015, 39, 329.

15. Cremasco, H.; Galvan, D.; Angilelli, K. G.; Borsato, D.; de Oliveira, A. G.; Food Sci. Technol. 2019, 39, 173.

16. Haykin, S.; Neural Networks, a Comprehensive Foundation; Prentice Hall: New Jersey, 2001.

17. Borsato, D.; Pina, M. V. R.; Spacino, K. R.; dos Santos Scholz, M. B.; Androcioli Filho, A.; Eur. Food Res. Technol. 2011, 233, 533.

18. Bona, E.; Borsato, D.; Bassoli, D. G.; Acta Sci. Technol. 2012, 34, 111.

19. Cremasco, H.; Borsato, D.; Angilelli, K. G.; Galão, O. F.; Bona, E.; Valle, M. E.; J. Sci. Food Agric. 2016, 96, 306.

20. Walkoff, A. R.; Antunes, S. R. M.; Arrúa, M. E. P.; Silva, L. R. C.; Borsato, D.; Rodrigues, P. R. P.; Electron. J. Chem. 2017, 9.

21. Lemes, M. R.; Pino Júnior, A. D.; Quim. Nova 2008, 31, 1141.

22. Kohonen, T.; Maps, S. O.; Springer Series in Information Sciences, 1995, vol. 30.

23. Borsato, D.; Moreira, M. B.; Moreira, I.; Pina, M. V. R.; Silva, R. S. dos S. F.; Bona, E.; Food Sci. Technol. 2012, 32, 281

24. Comsol Multiphysics ${ }^{\circledR}$, version 5.2; COMSOL, Inc., Burlington, MA, USA, 2016.

25. Matlab ${ }^{\circledR}$, version 7b; The MathWorks Inc.; Natick, MA, USA, 2007.

26. Statistica Software for windows, version 2018/13.4; Tulsa, OK, USA, 2007.

27. Bishop, C. M.; Neural networks for pattern recognition; Oxford University Press: New York, USA, 2007.

28. Hill, T.; Lewicki, P.; Statistics: methods and applications: a comprehensive reference for science, industry, and data mining; StatSoft, Inc.: Tulsa, 2006. 